\title{
Critical Thinking in Education: Globally Developed and Locally Applied
}

\author{
Mansoor Fahim \\ Allameh Tabataba'i University, Iran \\ Email:dr.mfahim@yahoo.com \\ Mohammad Reza Ghamari \\ Allameh Tabataba'i University, Iran \\ Email: dr_m_rezaghamary2@yahoo.com
}

\begin{abstract}
Critical Thinking encompasses a set of skills including the ability to assess reasons properly, probe into pertinent evidence and figure out fallacious arguments in educational settings. Developing critical thinking or promoting the ability to think critically is a prime goal of education (Birjandi and Bagherkazemi, 2010; Bailin et al., 1991a,). A key factor to improving educational standards is training teachers into employing classroom strategies that encourage critical thinking. This paper wishes to take a fundamental look at the application of critical thinking to education in an Iranian context through analyzing its scope, significance, the need for, and strategies employed to enhance critical thinking (CT) in educational contexts.
\end{abstract}

Index Terms — critical thinking, education, strategies, enhancement, educational contexts, pedagogy

\section{INTRODUCTION}

Leafing through the literature on critical thinking (CT), one can infer that it means different to different people. The aim of this article is to review the raison d'être for critical thinking and its influence on education. It can be defined as the degree to which students report applying previous knowledge to new situations to solve problems, reach decisions, or make critical evaluations with respect to standards of excellence. CT is described as a form of higher order cognitive engagement; students who use deep strategies may then demonstrate greater levels of critical thinking, relative to students who tend to use surface strategies. Wright (2002) introduces a set of rationales for teaching CT among which are the following:

- As citizens, we have to make decisions about who to vote for and what stance to take on issues.

- Understanding any discipline or subject area requires that we understand and critique the claims made within that discipline.

- CT can help us sort out conflicting claims we often confront.

- CT is useful in making personal decisions.

- CT would intercept emotional judgments on moral issues.

- If we want our children to become independent decision makers, we should teach them how to think critically.

- Winning arguments becomes easier through critical thinking.

Within the framework of skepticism, CT is synonymous with informal logic. According to Shaffer (2005), the standards for what is considered critical thinking in many other contexts can be less rigorous and should be examined carefully on a case by case basis (p.103).

\section{A. Annals of Critical Thinking}

The notion of critical thinking is by no means new. Socrates, more than 2000 years ago realized that people cannot justify their claims easily. In order to justify one's claim Socrates believed that seeking reasons, obtaining evidence, questioning assumptions, analyzing concepts, and figuring out the implications of what was believed and acted upon were all necessary. The foundation of western philosophy was also erected by other Greek scholars such as Plato and Aristotle originating in Socrates' ideas. Rene Descartes in his Rules for the Direction of the Mind, emphasized the importance of subjecting all beliefs to critical scrutiny.

Five philosophers of education namely, Robert Ennis, Richard Paul, John McPeck, Harvey Siegel, and Jane Roland Martin hold differing and debatable perspectives on CT.

Ennis (1996) defends a conception of critical thinking based primarily in particular skills, such as a observing, inferring, generalizing, reasoning, evaluating reasoning, and the like. For him, critical thinking is the correct assessing of statements. Like Ennis, Paul (1982) emphasizes the skills and processes associated with critical thinking. He distinguishes critical thinking in the weak sense from critical thinking in the strong sense. Unlike Ennis and Paul, McPeck (1981) argues that critical thinking is specific to a particular discipline, and that it depends on the thorough knowledge and understanding of the content and epistemology of the discipline. For him, critical thinking cannot be 
taught independently of a particular subject domain. Siegel stresses a strong conceptual connection between critical thinking and rationality. For him, critical thinking means to be appropriately moved by reasons. Martin (1992) emphasizes the dispositions associated with critical thinking, and suggests that it is motivated by and founded in moral perspectives and particular values.

\section{B. Scope of Critical Thinking}

Rationality and critical thinking form 'an ideal appropriate to all education and to all students' (Siegel, 1997, p.2). The emphasis on rational autonomy in educational aims has resulted in a curriculum and an implied view of personhood that stresses the achievement of certain standards in critical thinking as a priority. For some, Doddington believes as cited in Mason (2008) "priority extends beyond education with the suggestion that critical thinking has a central value for society itself".

There is some debate in the field as to whether critical thinking is generalisable or domain-specific. Wright (2002) points out that without critical thinking, there would be little human progress and employers want people who can think critically. The domain extends from personal decisions to online oral arguments.

Mason (2008) considers critical thinking as the ability to use a range of information derived from many different sources, to process this information in a creative and logical manner, challenging it, analyzing it and arriving at considered conclusions which can be defended and justified. To analyze critical thinking, empathy, culture and history are to be taken into account. This viewpoint has been supported by Mason through the definitions offered for CT (ibid., p. 22). It is the understanding of a problem and how to evaluate the problem in various situations.

It is thinking about an issue or problem without allowing conventional limits, boundaries and conventions to restrict the generation of your analysis or solution. CT covers the evaluation of many different sources such as the work of writers of articles, journals or books and the use of serial sources of written information. Perhaps the most direct challenge in relation to the domain of critical thinking is in the practices of problem-solving and decision- making.

The notion of critical thinking appears in a number of areas of education. It is relevant to all learners despite the fact that the term is used much more in the arts and humanities, and less in the sciences. However, in what might be seen as a subject that bridges humanities, science and psychology, Moon (2008) believes the literature would suggest that critical thinking is seen as particularly important.

\section{The Need for CT in Educational Contexts}

We all know that the world is changing rapidly and everyday humans are faced with new questions in all walks of life including education. CT is not only concerned with substantive phenomenal issues such as decisions on nuclear disarmament, cloning, or religious radicalism, but also can be associated with as simple issues as a minor decision made by a teacher about an unruly student in the classroom. In Wrights' words, we seem to be able to solve all kinds of technical problems, such as how to build a space station or develop a faster computer chip, but we do not seem to fare so well with problems involving our social and personal lives. Science cannot answer questions about what we should do or what is good or bad. It cannot tell us who makes a good friend. It is here that critical thinking has practical values.

Our geography of thought in this paper shows various educational needs for critical thinking. In a critical thinking course, it is very common that students are taught to apply a set of fundamental principles of logic and to avoid falling into the traps of a number of fallacious or biased patterns of thinking mostly politically directed. Mason (2008, p.61) points out that the complexity involved in putting logical reasoning into practice has often been neglected and students often find it difficult to apply the fundamental principles in their academic work. The students need the ability to apply them.

Teachers, also, need to be able to use critical thinking in the task of teaching. If teachers, Mason (2008, p.6) believes, had a better understanding of the adaptive character of human reasoning, they would appreciate that students' logical reasoning also has to be trained in a domain-specific or context- sensitive way. In other words, the ability to reason needs to be developed and that it takes time for students to master this ability and use it in different contexts.

One of the crucial aspects of critical thinking is to realize that we all reason from within a point of view. We have to analyze and evaluate our point of view and recognize and evaluate those of others. If we do not do so, we are likely to become dogmatic and prejudiced, and we will miss the opportunity to consider perspectives that could be valuable. Not recognizing the validity of others' points of view is disrespectful but accepting them without judgment can be dangerous also. According to Richard Paul (1994), a point of view is made up of purposes, questions, evidence, beliefs, a language, and conclusions and decisions. Identifying, understanding, and evaluating points of view is vital in all subject areas and in all phases of school life this leaves us to consider how we can help students think critically about the values that often shape viewpoints. None of the activities described so far can occur in classrooms where right answers are always expected. Building a classroom community of thinkers is important for a couple of reasons. First, critical thinking is not a set of abilities that one uses from time to time, like the abilities used when swimming or riding a bike. Critical thinking is a way of approaching almost everything in and out of the classroom. Second, the classic image of the lone thinker is misleading; we should not expect to be able to think through all our problems by ourselves. Just imagine classroom groupwork; this approach provides a far superior education. We can learn from one another. But many children may be unwilling or unable to involve themselves in group discussions. They may not listen well, react badly to what they perceive as criticism when someone disagrees with them, and not know how to monitor what they 
say, or lack confidence in their ability to add to the discussion. To help develop the conditions necessary to create a community, we need to establish appropriate expectations, model critical thinking, design suitable activities, and teach them the tools for good critical thinking. As Wright recommends, everyone in the classroom should have the expectation that controversial matters can be discussed, as long as they are approached with caution. When disagreement exists, we all must be open to points of view other than our own. This may mean that we suggest to learners that they consider other points of view or that we present other points of view to them. We should tell children that critical thinking is not easy. If they know they cannot expect always to arrive at right answers, they will not become frustrated or discourage with issues that remain unclear. We also should expect the rules for good discussion to be respected: no one dominates the conversation, everyone listens attentively, participants ask questions of each other, they direct their remarks to each other (not just to the teacher), and they ask for and give reasons for their thinking and opinions.

If the one learners to be good critical thinkers, we must model the necessary attributes ourselves. We can do this in a number of ways. Initially, we should admit that we do not know the answers. This is not an admission of 'weakness': but not knowing is not the same as presenting ourselves as idiots. Critical thinking simply cannot flourish in classrooms where teachers think they know everything (Wright, ibid.).

If students need to be more aware of the natural and cultural contexts in which their thinking patterns are embedded, they should become more sensitive to their own ways of thinking and as Mason (ibid.) concludes, less likely to misapply them or make hasty judgements based on them.

\section{Pedagogy of Critical Thinking}

Providing an overview of pedagogical issues in CT, we try to identify some principles on which it is based. Although thinking and representation of thinking are different, they are used interchangeably because of having much in common. The notion of depth in CT is closely associated with the level of epistemological development of the thinker (Moon, 2008, p. 126). The variation in depth and its association with epistemological development indicate that critical thinking develops as a capacity and that this development needs to be taken into account in pedagogical thinking (ibid.).

The aims of a pedagogy of CT, according to Moon (2008) are to enable learners to:

- Shift from an absolutist conception of knowledge towards contextual knowing (in Baxter Magolda's terminology);

- Shift from superficial or descriptive responses to critical issues, towards depth in response;

- Understand the context in which CT is required, and to respond at the appropriate depth;

- Display flexibility in thinking;

- Use creativity in CT in an appropriate manner;

- Discuss issues of objectivity and subjectivity with respect to their thinking processes.

The point that is often lost about CT is that the nature of an individual is under the control of that individual and one person cannot make another think critically, rather facilitate or faster it through different strategies. Meyers (1986) advocates it and asserts' we facilitate or foster CT through the tasks set, the habits formed by learners, the careful provision of feedback and the understanding of the teacher and the classroom atmosphere.

There are a number of major strategies for encouraging CT. However, we assume no one can claim that a strategy is the absolute right or absolute wrong. Lipman (1991) suggests that CT is facilitated through the teaching of philosophy to all students. This view is exemplified in the pattern of the International Baccalaureate (IB) in which there is a study of 'Theory of Knowledge' alongside several other disciplines (International Baccalaureate, 2005).

Brookfield (1987), as an example of a strategy, advocates the introduction of CT as a topic apart from the disciplines studied. In line with Brookfield's position, Carey and smith (1999), talking about younger students, suggest that there may often be a discrepancy between the stage of a 'common-sense' learning and the stage that drives thinking on scientific work at school or college. So, the possibility of work at more sophisticated levels of thinking when the topic is related to everyday life is suggested (Moon, 2008, p. 131).

Some interesting principles worth mentioning:

- The support of CT development in a student needs to be responsibility of all staff who work with students.

- All teaching should challenge the learner to shift his/her thinking along the epistemological development continuum as well as developing CT.

- The significance of the atmosphere of a class needs to be recognized.

- The classroom should feel as if it easily tolerates risk-taking.

- Deliberately encouraged interaction between students should be developed.

- The kind of assessment clarifies what we require from learners.

- Learners should be provided with examples of CT showing the quality or standard of work expected.

\section{A. Encouraging CT in Educational Contexts in Iran}

During the past 20 years numerous conferences, journals, curriculums and programs have been developed and allocated to CT. The impact of CT in education has been summarized by Wright (ibid) as helping children grapple with 
the subject matter in a more profound way; it helps them make decisions; it helps them understand and critique other points of view; it helps develop competent, responsible citizens.

Alan Sears and Jim Parsons (1991) outlined a number of characteristics that teachers must embody if they want to encourage critical thought in students.

- We have to accept that knowledge can be subject to change.

- We have to encourage the asking of questions-any questions, even ones that challenge our own beliefs.

- We have to seek out and have empathy for alternative viewpoints.

- We have to tolerate ambiguity.

Far back in 1947, William Sumner the American anthropologist, highlighted the significance of CT in educating the society: the critical habit of thought, if usual in a society will pervade all its conventions, because it is a matter of taking up the problems of life. Men educated in it cannot be stampeded by stump orators. They are slow to believe. They can wait for evidence and weigh evidence, uninfluenced by the emphasis or confidence with which assertions are made on one side or the other. They can resist appeals to their dearest prejudices and all kinds of cajolery. Education in the critical faculty is the only education to make good citizens. Although young children (and many adults) are not endowed with the disposition to think critically, they have the potential to develop and build on it through proper training. One lesson that children and adults have to learn is that not everything we think is true actually is true. Children can learn that their truth is not necessarily someone else's truth and can be helped to sort out which assertions are to be believed and which are not. When children get to school, I often think that we discourage rather than encourage the disposition to ask questions (Wright, ibid).

Examining the relationship between Iranian EFL teachers' critical thinking ability and their student-evaluated professional success, Birjandi and Bagherkazemi (2010) concluded that better critical thinkers turned out to be better EFL teachers.

We can think critically about whether a work of art is excellent or whether a career in teaching is worthwhile. In all the above, we need background knowledge, the ability to establish criteria or to evaluate those that are pre established, skills of argument, strategies for arriving at decisions, and the dispositions necessary to be a critical thinker.

\section{B. Bloom's Taxonomy of Critical Thinking and Reforms in Iranian Educational Policies}

Benjamin Bloom describes the major areas of the taxonomy in the cognitive domain. As Bellis (2011) put it, the taxonomy begins by defining knowledge as the remembering of previously learned material. Knowledge, according to Benjamin Bloom, represents the lowest level of learning outcomes in the cognitive domain. Knowledge is followed by comprehension, the ability to grasp the meaning of material and goes just beyond the knowledge level. Comprehension is the lowest level of understanding. Application is the next area in the hierarchy and refers to the ability to use learned material in new and concrete principles and theories. Application requires a higher level of understanding than comprehension.

The next area of the taxonomy is analysis in which the learning outcomes require an understanding of both the content and the structural form of material. Next is synthesis, which refers to the ability to put parts together to form a new whole. Learning outcomes at this level stress creative behaviours with a major emphasis on the formulation of new patterns or structures. The last level of the taxonomy is evaluation. Evaluation is concerned with the ability to judge the value of material for a given purpose. The judgements are to be based on definite criteria. Bellis (2011) believes that learning outcomes in this area are the highest in the cognitive hierarchy because they incorporate or contain elements of knowledge, comprehension, application, analysis, and synthesis.

Forehand (2011) holds that throughout the years, the levels have often been depicted as a stairway, leading many teachers to encourage their students to "climb to a higher (level of) thought." The lowest three levels are: knowledge, comprehension, and application. The highest three levels are: analysis, synthesis, and evaluation.

During the 1990's, a former student of Bloom's, Lorin Anderson, led a new assembly which met for the purpose of updating the taxonomy. This time "representatives of three groups [were present]: cognitive psychologists, curriculum theorists and instructional researchers, and testing and assessment specialists"(Forehand, 2011). Published in 2001, the revision includes several seemingly minor yet actually quite significant changes. Several excellent sources are available which detail the revisions and reasons for the changes. A more concise summary appears here. The changes occur in three broad categories: terminology, structure, and emphasis.

Many revolutions are underway around the world. CT is the area that has drawn the attention of Iran's policy makers especially in education. Some doubts have been cast over the trend of university entrance examination and better criteria especially from CT approach are going to be applied. The previous trend of assessment relied more on the lowest level of Bloom's taxonomy, knowledge. The new trend has a tendency toward the increasing the students' ability to applying the previous knowledge to new context.

\section{StRATEGIES EMPLOYED TO ENHANCE CT IN EDUCATIONAL CONTEXTS}

Focusing on the how rather than what, three methods were suggested by Wright (2002) on teaching critical thinking. We can teach a separate course or units, we can infuse critical thinking into that we teach, or we can use a mixed approach. 
The first approach of a separate course or unit requires materials that teach specifically for critical thinking dispositions, skills, and knowledge. Infusion, the second possible approach, requires that critical thinking be taught as an integral part of all subject areas. The benefits of combining the two basic approaches should be obvious, but whatever approach is taken needs to be adapted to the context. Of course to design activities that foster critical thinking about concepts, we first have to understand the attributes of the concepts to be taught. Wright (ibid.) suggests two basic questions to be posed by critical thinkers:

- Is what we are told true (including the observations and others)?

- Are observations reliable?

Scholars have developed many criteria which are not limited to a particular country. Ennis' criteria are best understood in an Iranian educational setting. Robert Ennis (1996), identifies the following criteria for evaluating the credibility of authorities or experts:

- The person has knowledge and expertise.

- The person has a good reputation.

- The person tells the truth in general and is usually correct in the area under discussion.

- What the person says is in agreement with others who are equally qualified.

- The person is careful in what is said; the matter is given thought.

- The person has no apparent conflict of interest.

- The person follows established procedures in arriving at the information.

- Person is aware that his or her reputation can be enhanced or damaged if what if he or she says is found to be true or false.

- The person can give reasons for saying that her or his statements are true.

Norris and King (1985), identify criteria they feel must be made for an observer to be considered reliable:

- Does not allow emotion to interfere

- Has no conflict of interest

- Has senses that function properly

- Has a good reputation

- Uses appropriate observation instruments

- Was in a suitable physical position to observe

- Makes statements that are confirmed by others, or are confirmable

Wright underscores a number of ways we can enhance critical thinking using classroom routines and activities:

- We regularly use the vocabulary of critical thought.

- We consider the topic of the unit of the study

- We create assignments that call for critical thinking

- When topics seem not to lend themselves to critical thinking, we create activities that promote it

- We regularly ask children to peruse curriculum materials, newspapers and other media sources to identify the points of view from which they are written, along with any biases, stereotypes, and fallacies in reasoning.

- We consider learners' ideas seriously and use criteria that they generate for evaluation purposes

- The ask learners to consider issues from points of view other than their own.

- We ask a lot of questions and expect class members to do the same.

There are many strategies developed to enhance CT among which we can refer to three major areas.

\section{A. Encouragement of CT through the Process of Assessment}

Critical thinking is involved in assessment in a number of ways.

1. Involving learners in the development of assessment criteria.

If students are to be engaged in the development criteria, a decision needs to be made as which kind of criteria are to be developed - threshold criteria, or those associated with marking, grading criteria (Moon, 2002). Students, in groups, generate some appropriate assessment criteria based on the sample given. The list of collected criteria is reconsidered and a suitable number are selected.

2. Peer assessment

It involves students in marking the work of their peers on the basis of the given criteria. A general principle if we are to get learners involved in looking at each other's work, is that they understand the difference between being critical in a negative manner and being constructive.

3. Self-assessment

Here, students assess their own work against a set of criteria. They thereby learn metacognitive skills and learn to make judgements and gradually learn to do their work better.

4. Testing as a means of fostering critical thinking

Young (1980c) holds that one means of encouraging learners to develop CT skills is the use of tests. This will enable them to learn where they are working appropriately and where inappropriately - so long as the test matches the conception of critical thinking.

In all of them there is something in common. The element of judgment is observed in all criteria. So, we might claim that in the process of assessment of critical thinking, practice of judgement is provided. 


\section{B. Critical Thinking Developed through Oral Work}

It is valuable to encourage the oral expression of ideas. Moon (ibid.) believes that self-expression is an important self-development skill and the exposure to the views of others helps learners to recognize the need to take multiple perspectives into account in the process of critical thinking. Many forms are introduced to be useful: debate, group critical thinking tasks under time pressure, quick think, conversational questions, critical friends, other literature relating to the oral aspect of critical thinking.

Landis et al. (2011) point out that computer mediated communication (CMC) provides a social context for learning that gives learners time to think about their contributions and organize their thoughts prior to responding. Most educators who have worked extensively with online education realize that determining whether this form of teaching can have a positive effect on students' level of critical thinking, is an important area of inquiry. Their study cast doubt on the reliability of instruments used during the assessment of that kind of discourse.

Other studies confirm that the enhancement of students' critical thinking ability is influenced by different strategies among which we refer to those suggested by Brahler, et al. (2002). They pointed to the learning environment, the social context of the learning environment, and the instructor's approach to teaching. 'Nontraditional instructional approaches that support student-centered, small group collaborative learning may enhance student critical thinking skills and result in high-quality educational outcomes (p. 220). Debate is designed to enact critical thinking. Tutorial groups can be good situations for debate. Care should be taken that everyone gets involved. One way of ensuring the involvement is to prepare a case either for or against.

\section{Writing and Critical Thinking}

The links between critical thinking and writing go beyond the process of getting the content of the critical mind onto paper or screen. The production of a written version of thoughts provides a chance for review. So the writer of a text can judge whether the material on paper or screen says what s/he needed to say, and s/he duly revises it, or not. Once thinking is represented in writing, it can be seen, assessed and judged by others. Exercises in writing skills may concern the skills of writing that are associated with critical thinking or critical thinking as represented in writing. Below appear some areas of writing tasks:

\section{Writing tasks that aim to improve the representation and process of $\mathrm{CT}$ in the early stages}

Moon (ibid.) introduces five exercises that, she believes, are particularly useful for students in the early stages of critical thinking.

1. Summarizing and the ability to write a conclusion.

2. Summarizing the evidence.

3. Taking different disciplinary perspectives.

4. Making a judgement.

5. Making a judgement, starting from another perspective.

We don't see any problems with the above exercises. However, we don't know the reason behind the number of exercises. There is no need to introduce the last two exercises. In all processes of critical thinking the element of judgement is present and all exercises involving critical thinking contain judgement.

\section{Writing tasks to further the capacity in critical thinking}

The next set of exercises appears useful for students in the middle or towards the end of their undergraduate studies.

1) The use of concept maps

2) A fictitious debate

3) Practice of peer review skills

4) Mark an essay in which critical thinking is represented

5) Recognition of the roles of referencing in the written form of CT

6) Recognition and development of the 'playing with ideas' form of writing

7) 'Compare and contrast' tasks

8) Finding different perspectives on the same issue

\section{Reading and Critical Thinking}

Many of the activities listed in the section on writing and critical thinking would be relevant to the development of reading skills since there is mutual reinforcement in the processes. Moon (ibid.) the role of purpose in reading critically is very important. A sense of purpose should direct the criticality. As in writing, there are generic skills involved in reading, in addition to those directly associated with critical processes.

As in many activities, however, there are two activities involved in reading- the mental reading process and the representation of that reading, the notes made (Moon 2008, p.156). Note making and recognizing the structure of text are the factors which are focused very much in reading critically.

\section{CONCLUSION}

This article gains insights into the significance, necessity of teaching and learning of critical thinking. CT can empower people to reason well about problems and issues. We should accept the fact that students have to make 
judgements from time to time and a critical thinker is a person who makes appropriate judgements in particular circumstances. Also, some of the major strategies employed to teaching critical thinking were introduced and evaluated. To conclude, believing that the notion of CT appears in a number of areas especially in education, we need to bear in mind that critical thinking needs to be encouraged, developed and practiced through employing certain educational strategies due to the kind of skill we choose to reinforce.

\section{REFERENCES}

[1] Bailin, S., Case, R., Coombs, J. and Daniels, L. (1999). 'Common misconceptions of critical thinking', Journal of Curriculum Studies, 31 (3), 269-283.

[2] Baxter Magolda, M. (1992). Knowing and Reasoning in College Students; gender-related patterns in students' intellectual developments, San Francisco: Jossey-Bass.

[3] Bellis, Mary. (2011). Benjamin Bloom's Model of Critical Thinking. Adapted from materials written by the USPTO. Retrieved on June $12^{\text {th }}, 2011$ from www.Bloom's Taxonomy.

[4] Birjandi, Parviz \& Bagherkazemi, Marzieh. (2010). The Relationship between Iranian EFL Teachers' Critical Thinking Ability and their Professional Success. English Language Teaching Vol. 3, No. 2: 135- 145.

[5] Brahler, C. Jayne, Quitadamo, Ian J. and Johnson, Emily C. (2002). Student critical Thinking is Enhanced Using Online Learning Modules by Developing Exercise Prescriptions. Advance in Physiological Education 26:210-221, 2002. Retrieved on May $20^{\text {th }}, 2011$ from www. Critical thinking and education.

[6] Ennis, R. (1996). Critical Thinking (Upper Saddle River, N), New Jersey: Prentice-Hall.

[7] Harpaz, Yoram. (retrieved in April 2011). Conflicting Logics in Education to Critical Thinking. www. Critical thinking. Mandel School.

[8] International Baccalaureate. (2005). Website for International Baccalaureate in relation to theory of knowledge, www.ibo.org/diploma/curriculum/core/knowledge (accessed June 2006).

[9] Landis, Melodee et al. (2011). Evaluating Critical Thinking in Class and Online: Comparison of the Newman Method and the Facione Rubric. University of Nebraska-Omaha. Wichita State University. Communication Disorders Quarterly 28:3 • pp. 135-143 Downloaded from cdq.sagepub.com by guest on May 31th, 2011.

[10] Martin, J. R. (1992). Critical Thinking for a Humane World, in: S. Norris (ed.), The Generalizability of Critical Thinking: Multiple perspectives on an educational ideal. New York: Teachers College Press.

[11] Mason, M. (2008). Critical Thinking and Learning. Oxford: Blackwell Publishing.

[12] McPecK, J. (1981). Critical Thinking and Education, Oxford: Martin Robertson.

[13] Meyers, C. (1986). Teaching Students to Think Critically, San Francisco, Jossey-Bass.

[14] Moon, Jennifer (2008). Critical Thinking. London: Routledge.

[15] Norris, S., \& R. King. (1985). Test on Appraising Observations. St. John's, Nfld.: Institute for Educational Research and Development, Memorial University.

[16] Young, R. (1980c).'Testing for critical thinking', in R. Young, Fostering Critical Thinking, New Directions for Teaching and Learning, San Francisco, Jossey-Bass, pp. 77-99.

[17] Paul, R. (1994). Critical Thinking: What Every Person Needs to Survive in a Rapidly Changing World. Rohnert Park, CA: Center for the Study of Critical Thinking, University of Sonoma.

[18] Paul, R. (1982). Teaching Critical Thinking in the 'Strong Sense': A focus on self-deception, world views, and a dialectical mode of analysis, Informal Logic Newsletter, 4:2. 42-53.

[19] Plato (1987). Plato: The Republic, trans. D. Lee, Harmondsworth: London: Penguin.

[20] Sears, A. \& J. Parsons (1991). "Toward Critical Thinking as an Ethic". In Theory and Research in Social Education. Vol. 19, no. 1. 31-39.

[21] Shaffer, Lawrence (2005). Encyclopaedictionary of Literary Criticism. Dehli: IVY Publishing House.

[22] Siegel, H. (1997). Rationality Redeemed? Further dialogues on an educational ideal. New York: Routledge.

[23] Sumner, W. (1959). Falkways. New York: Dover.

[24] Wright, J. (2002). Is That Right? Lancaster: Pippin Publishing.

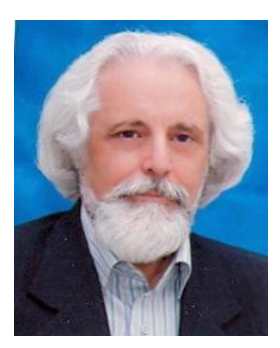

Mansoor Fahim was born in Nahavand in 1946. He received a Ph.D. in TEFL from Islamic Azad University in Tehran, Iran in 1993. As for his professional background, he was a member of the faculty of English Language and Literature at Allameh Tabataba'i University in Tehran, Iran from 1981 to 2008 when he was retired as an associate professor of TEFL. He has taught English at a welter of universities. At present, he runs Research methods, Psycholinguistics, Applied Linguistics, Second Language Acquisition, and Seminar classes at M.A. level and First Language Acquisition, Psycholinguistics, and Discourse Analysis courses at Ph.D. level at a number of universities including Allameh Tabataba'i and Islamic Azad Universities. Moreover, he has several published articles and books mostly in the field of TEFL and has translated some books into Farsi.

Dr. Fahim is currently a member of the editorial board of some Iranian journals of Applied Linguistic Studies.

Mohammad Reza Ghamari was born in Toyserkan in 1967. He received a B. A. in English Language and Literature from Shahid Beheshti University in Tehran and an M.A. in TEFL from the Islamic Azad University in Najafabad, in 2006.He is currently a Ph.D. student of TEFL at Allameh Tabataba'I University, and a faculty member of Iranian Police University. As for his professional background, he has taught the English course at various universities. Moreover, he has published a few articles and 5 books. 